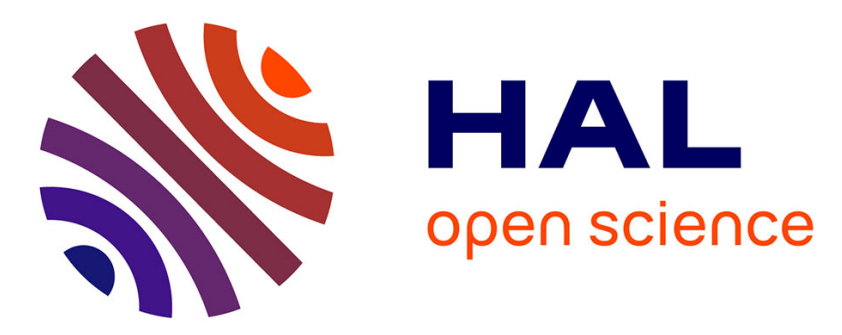

\title{
A Method for Lifecycle Design of Product/Service Systems Using PLM Software
}

Tomohiko Sakao, Yang Liu, Rolf Gustafsson, Gabriel Thörnblad

\section{To cite this version:}

Tomohiko Sakao, Yang Liu, Rolf Gustafsson, Gabriel Thörnblad. A Method for Lifecycle Design of Product/Service Systems Using PLM Software. 14th IFIP International Conference on Product Lifecycle Management (PLM), Jul 2017, Seville, Spain. pp.710-718, 10.1007/978-3-319-72905-3_63 . hal-01764170

\author{
HAL Id: hal-01764170 \\ https://hal.inria.fr/hal-01764170
}

Submitted on 11 Apr 2018

HAL is a multi-disciplinary open access archive for the deposit and dissemination of scientific research documents, whether they are published or not. The documents may come from teaching and research institutions in France or abroad, or from public or private research centers.
L'archive ouverte pluridisciplinaire HAL, est destinée au dépôt et à la diffusion de documents scientifiques de niveau recherche, publiés ou non, émanant des établissements d'enseignement et de recherche français ou étrangers, des laboratoires publics ou privés. 


\title{
A method for lifecycle design of product/service systems using PLM software
}

\author{
Tomohiko Sakao, Yang Liu \\ Division of Environmental Technology and Management, Department of Management and En- \\ gineering, Linköping University, SE-581 83 Linköping, Sweden \\ tomohiko.sakao@liu.se, yang.liu@liu.se \\ Rolf Gustafsson, Gabriel Thörnblad \\ Maxiom AB, SE-413 28 Göteborg, Sweden \\ rolf@maxiom.se, gabriel@maxiom.se
}

\begin{abstract}
Environmental sustainability and resource scarcities are urgent issues, and innovative ways of providing products and services are needed. In light of a circular economy, manufacturers have yet to learn and implement innovative ways of design covering the entire product lifecycle and incorporating sustainability and resource issues based on system perspectives. This paper aims at proposing an innovative and practical method to support manufacturers in the design of a product/service system (PSS) for resource efficiency and sustainability. The intention is that the method be implemented as an add-on feature for commercial PLM (product lifecycle management) software, with a lifecycle focus, including calculation of lifecycle cost (LCC).
\end{abstract}

Keywords: commercial PLM software, LCC (lifecycle cost)

\section{Introduction}

Environmental problems and resource scarcities are forcing rapid changes in manufacturing firms, and innovative ways of providing products and services are needed. In light of the circular economy [1], manufacturers acknowledge the importance of resource efficiency and technology to survive in global competition. To increase resource efficiency by circular flows of materials, the lifecycle perspective is critical, and design is the most influential activity on the lifecycle. In addition, services such as take-back, repair, and repurpose are often provided effectively with products by manufacturers, where such an offering is often called a product/service system (PSS) [2].

Despite academia's advances in scientific methods for lifecycle design of products and services, manufacturers, especially small and medium-sized enterprises (SMEs), have yet to learn and implement innovative ways of design covering the entire product lifecycle and incorporating resource issues. This is the challenge targeted by the paper

adfa, p. 1, 2011.

(C) Springer-Verlag Berlin Heidelberg 2011 
because, according to a thorough review in the area [3], virtually no practical solution is available to fill this gap.

Manufacturing firms, even SMEs, often utilize CAD (computer-aided design) and/or PLM (product lifecycle management) software in their routines to design their products. The paper takes these tools as an excellent opportunity to build a practical solution. As a first step, the paper aims to propose an innovative and practical method to support manufacturers in their design of a PSS lifecycle from the environmental and economic perspectives. The intention is to implement the method as an add-on feature for a commercial PLM software package.

\section{Related works}

\subsection{Ecodesign methods and tools}

For increasing resource efficiency, design is seen as a key activity because it has a high impact on the performance of a designed product and/or service [4]. There have been numerous methods and tools proposed over the last two decades to support design for resource efficiency (see e.g. a review by [3]). The most widely known are a checklist method, e.g. [5], and lifecycle assessment (LCA). Both of these are effective for assessing a product from an environmental viewpoint. Even a discussion of how to implement environmental assessment scientifically in CAD software is available; see e.g. [6]. Another type is a method with a specific purpose, e.g. Design for Disassembly (DfDA) [7, 8] and Design for Remanufacturing [9]. However, most of these methods/tools focus on the environmental aspect and fail to consider business issues [10]; in other words, they focus on "design for social virtue" [11]. This is a fundamental problem that creates barriers for companies to use those methods/tools. A method needs to be embedded in a "must do" process for designers in order to be used in industry [12]. This is an especially relevant issue for SMEs, who are often unable to afford to use a method/tool that does not directly address the economic aspect, with the exception of regulations [13].

In light of the circular economy, which emphasizes economic benefits for companies [14], one competitive edge that is economically attractive to manufacturing firms today, even to SMEs as reported in [15], is integrating services (e.g. upgrade, maintenance, repair, product reuse, part reuse, repurpose, take-back, and remanufacturing) with physical products in design [16]. This way of offering both product and service is a pragmatic approach to decrease environmental impacts in real business; in other words, it does not automatically mean reduced environmental impact, but it has high potential towards better environmental performance. This type of integration has been reported with offerings on the market in different sectors to have decreased environmental impacts (see e.g. $[17,18]$ ). This is in line with the frequent dominance of the use phase impact on the total lifecycle environmental impact, as discussed by e.g. [19]. Therefore, to guide designers to integrate products with services through economic motivation towards circularity is promising, even in terms of resource efficiency. There exist a few methods to support designers in such a manner that have been verified with industrial 
cases (e.g. [20, 21]. However, virtually no practical and simple solution is available today, especially for SMEs to be able to implement, according to different thorough reviews $[3,22]$.

\subsection{PLM software}

PLM software is designed to manage product-related information such as data, processes, business systems and people throughout the entire lifecycle of a product efficiently and cost-effectively, from ideation, to design and manufacture, to service and disposal [23]. There are many commercial PLM software applications. Some of the major diverse functions and technologies converge through PLM, including: product data management (PDM), computer-aided design (CAD), computer-aided manufacturing $(\mathrm{CAM})$, computer-aided engineering (CAE) and simulation.

Among these, PDM uses software to manage product and process-related data and information, such as CAD data, models, parts information, manufacturing instructions, requirements, and notes and documents, all in a central system.

According to one of the major PDM software vendors [23], the ideal system is accessible by multiple applications and multiple teams across an organization and supports business-specific needs, and the right PDM software can provide a company in any industry with a solid foundation that can be easily expanded into a full PLM platform.

Among the currently available commercial PLM software applications, none was found that significantly addresses the economic impact of products or PSSs, especially in the design phase. We aim to bridge this gap by introducing a new software concept which integrates the lifecycle cost (LCC) and lifecycle revenue (LCR) analysis in the traditional PLM software so that designers can evaluate the economic impacts during the design phase. The related works were reviewed, and there were merely a few; G.EN.ESI (Integrated software platform for Green ENgineering dESIgn and product sustainability), an EU FP7 project led by Germani, is one of the few public projects relevant to our concept $[24,25]$, and his research group published a series of articles [26-28]. The new concept introduced in this paper is developed to ensure its academic novelty.

\section{Proposed method}

\subsection{Overview}

Fig. 1 depicts the proposed method from the procedure viewpoint, and the steps with iterations are outlined below. The method builds upon the basic functions of an existing PLM software package. 


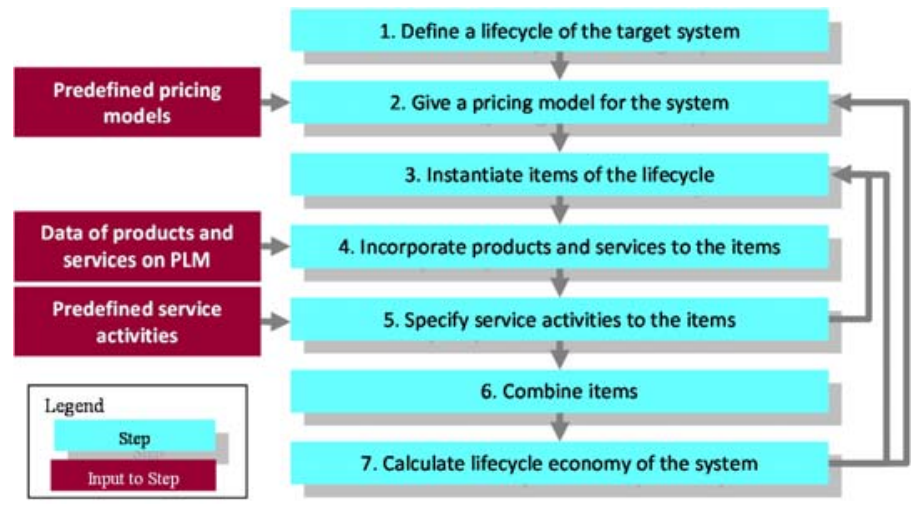

Fig. 1. Procedure with the proposed method

Step 1. Define a lifecycle of the target system - This definition includes the major function (functional unit in LCA), the length of the lifecycle and the boundary for the system to be designed and analysed.

Step 2. Give a pricing model for the system - A method user (i.e., a designer of the system) gives the pricing model by which the customer pays money to the provider from the predefined alternatives below.

1. A price given to the product sold and prices given to additional services in a sub-system or a system

2. A price given to a sub-system or a system with a specific time period or an applicable condition (e.g., running hours)

Step 3. Instantiate items of the lifecycle - First, the user determines the level of granularity of the parts and processes described. Based on the outcome of Step 1 and the granularity, each of the parts and processes is instantiated as an item in a PLM software package.

Step 4. Incorporate products and services to the items - As an option, data from products and services on the PLM software is linked to the items from the outcome of Step 3.

Step 5. Specify service activities to the items - Service activities, i.e. take-back, reuse, remanufacturing, and recycle, are associated to each item of the parts only. When each of the service activities takes place and how much it costs for the provider and the customer are also specified.

Step 6. Combine items - As an option, items defined in Step 3 are assembled as another item on a higher level in the hierarchy of the system structure. This step is sensible because different payment models may be given to items in the same system.

Step 7. Calculate lifecycle economy - The PLM software calculates the cost and revenue for the given lifecycle of the system. According to the result, a user is given an opportunity to carry out iteration. 
The overview of the software adopted in the proposed method as explained in the procedure above is depicted in Fig. 2. It involves basic functions of existing PLM applications as well as CAD software packages. Note that the new feature is shown with a shaded colour. The figure is explained in greater detail in the following sections.

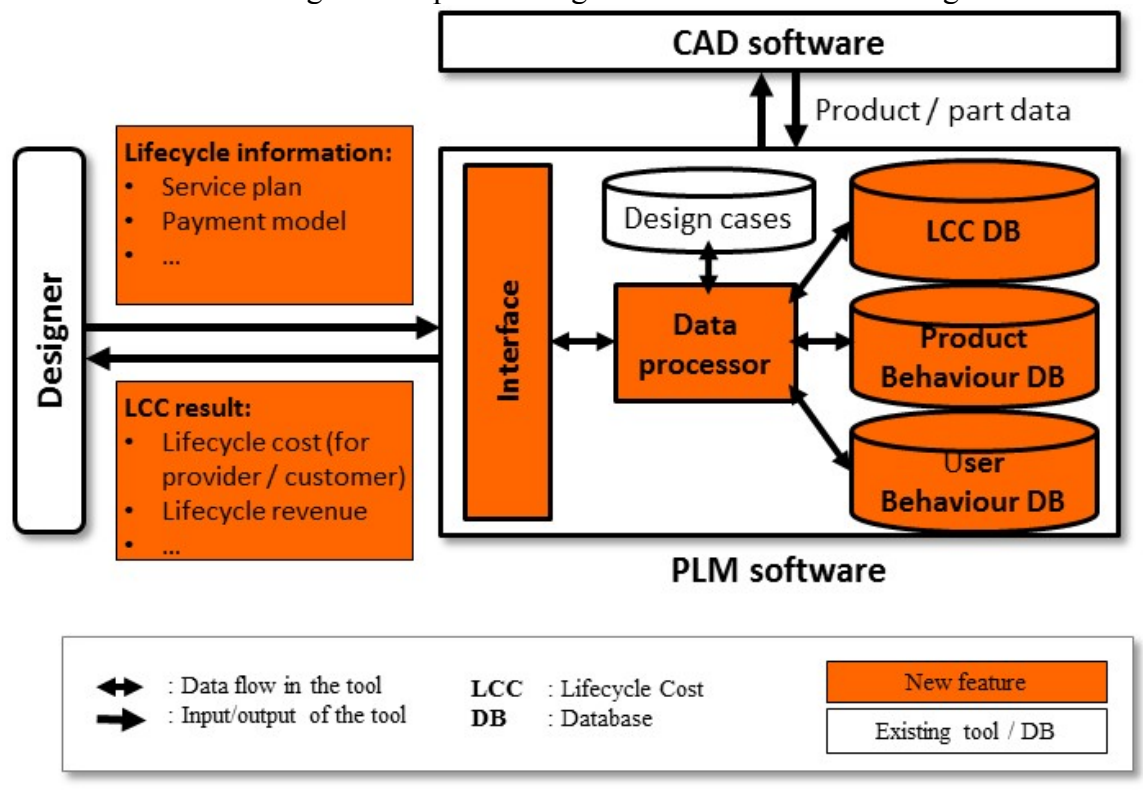

Fig. 2. Overview of the software adopted in the proposed method

\subsection{Base PLM software}

Our method adopts existing commercial PLM software as a base, which is already widely in use for companies who want to organize their information. We build a new add-on feature based upon the current platform.

PLM is a system that spans several departments and areas of a business. The objective of PLM is a system that grows, evolves and changes so that it always supports the company's internal processes and procedures. The PLM system shall be able to be loosely integrated with other systems, e.g. CAD systems and business systems.

The base PLM software that is chosen by meeting the above requirements is called YaPdm. It is a PDM and PLM system with CAD integrations, workflows, a bill of materials (BoM) report, processes, etc. The system consists of a server and client. On the server side there is an SQL database and a vault, and the program itself is installed on the client's desktop. The system provides the following functions.

- Document Management

All the documents and files can be structured and versioned. Templates, project structures and a set of attributes can easily be designed to answer all business needs.

- Integrations 
The CAD integrations ensure that the user is working with the right revisions of an assembly. The integrations to the Office programs synchronize the properties and attributes between the application and PLM.

- Item Management

By creating items and item structures, documents such as drawings and instructions can be linked to the items.

- Projects

To manage projects and related files, all documentation on a project is easily collected in one place. It is possible to control the project rights and status in the system.

- Revision Management

To keep track of all documents and files, all revisions are saved and can be filtered by approval date.

- Workflows

It is possible to create several approval flows and have control over what happens during the various steps in the process.

\subsection{New feature for calculating LCC for PSS}

As the main contribution of this paper, we aim to propose an innovative and practical method to support manufacturers in their design of PSS for resource efficiency and sustainability. This particularly requires addressing the economic and service aspects related to a lifecycle. Currently, there is no commercially available PLM software addressing such aspects when designing a lifecycle. The intention is that the proposed method be implemented as an add-on feature for existing commercial PLM software described in Section 3.1. The new added features mainly include a calculation of lifecycle cost for the manufacturer and customer, and lifecycle revenue for the manufacturer.

\section{The purposes of the new feature.}

- To improve the economic aspect of a system in question from the lifecycle perspective.

- To support a user of the software design services, i.e. take-back, reuse, remanufacturing, and recycle, within the system.

- To share, reuse and modify cases of previous designs of systems in an efficient manner.

- To describe the system for carrying out LCA outside the software.

\section{The functions of the add-on to be developed.}

- To receive information about services and the economic aspect of a system in question in an interactive manner with a user.

- To maintain links with the information on the base PLM software and the add-on.

- To calculate lifecycle costs of a system in question for the manufacturer.

- To calculate lifecycle revenues of a system in question for the manufacturer. 
- To calculate lifecycle costs of a system in question for the customer.

- To report the result of the calculations as a text file.

- To save and show design cases of previous designs of systems.

\section{The overall structure and key elements of the add-on.}

The overall structure of the software to be developed is depicted in Fig. 2.

\section{Lifecycle information.}

The lifecycle information is given to a specific system that is described on the software and includes:

- Service plan:

- Which service activities are applicable, i.e. take-back, reuse, remanufacturing, and recycle

- In which months to do a specific type of service of the system

- Which hardware to do a specific type of service in which months

- LCC (lifecycle cost) and LCR (lifecycle revenue) hierarchies

- Cost elements of a system

- Revenue elements of a system

LCC database (DB).

The DB stores economic data for:

- Products included in the system

- Services included in the system

- Product behaviour DB:

The DB stores a quantitative function to calculate the quality (to be degraded over time) of the product depending on the time from the start of the use and after maintenance.

- User behaviour DB:

The DB stores a quantitative function to decide the customer's choice depending on the quality of the product from alternatives as follows:

- Continue to use the product

- Order maintenance of the product

- Stop using the product

LCC result.

The LCC result depends on the lifecycle of the system and includes:

- Lifecycle cost (LCC) for manufacturer / customer

- Lifecycle revenue (LCR) for manufacturer

LCC and LCR are calculated as a summation based on the hierarchies defined in the software specification. 


\section{$4 \quad$ Concluding discussion}

The proposed software and method are expected to be used widely in the manufacturing industry because of its need, as described in Section 1. They could work as an innovative method for decision making in design and for follow-up in order to enhance resource efficiency from the lifecycle and system perspectives, because based on the literature surveyed [3, 22], no such method is available. As more information about things becomes available along the industrial megatrend of Internet of Things, it is expected to integrate information from sensors into the design phase. The software has a potential to function as an essential component to convey relevant lifecycle information to better design for e.g. reliability and remanufacturability. This paper presented an initial proposal of the method, and the method is yet to be validated.

\section{Outlook}

Future works include: 1. Implementation of the method as software, and 2. Evaluation of the method and the software with real cases from the manufacturing industry. The authors have been running a project with three manufacturing companies involved as lead users. Therefore, the plan is to apply the method and the software to cases from the three firms. Their systems are waste management systems, office furniture systems, and display systems at industrial fairs, which provide a substantial difference in terms of system lifetimes and thus opportunities to evaluate the method and the software in different circumstances. The reader is invited to contribute to the development of the method and the software, especially by offering an additional case from industry, as

this development is under a pressing need from our societies transitioning towards a sustainable world.

Acknowledgements. This research is supported by the Circularis (Circular Economy through Innovating Design) project funded by VINNOVA, Sweden's Innovation Agency (No. 2016-03267).

\section{References}

1. European Commission: Towards a circular economy: A zero waste programme for Europe. (2014).

2. Goedkoop, M.J., van Halen, C.J.G., te Riele, H.R.M., Rommens, P.J.M.: Product Service systems, Ecological and Economic Basics. (1999).

3. Umeda, Y., Takata, S., Kimura, F., Tomiyama, T., Sutherland, J.W., Kara, S., Herrmann, C., Duflou, J.R.: Toward integrated product and process life cycle planning-An environmental perspective. CIRP Ann. - Manuf. Technol. 61, 681-702 (2012).

4. Pahl, G., Beitz, W., Feldhusen, J., Grote, K.-H.: Engineering Design: A Systematic Approach. Springer London, London (2007).

5. Wimmer, W., Züst, R.: ECODESIGN Pilot: Product Investigation, Learning and Optimization Tool for Sustainable Product Development. Kluwer Academic Publishers (2001). 
6. Leibrecht, S.: Fundamental principles for CAD-based ecological assessments. Int. J. Life Cycle Assess. 10, 436-444 (2005).

7. Harjula, T., Rapoza, B., Knight, W.A., Boothroyd, G.: Design for Disassembly and the Environment. CIRP Ann. - Manuf. Technol. 45, 109-114 (1996).

8. Chang, H.T., Lu, C.H.: Simultaneous evaluations of material toxicity and ease of disassembly during electronics design: Integrating environmental assessments with commercial computer-aided design software. J. Ind. Ecol. 18, 478-490 (2014).

9. Hatcher, G.D., Ijomah, W.L., Windmill, J.F.C.: Design for remanufacture: a literature review and future research needs. J. Clean. Prod. 19, 2004-2014 (2011).

10. Sakao, T., Fargnoli, M.: Customization in ecodesign: A demand-side approach bringing new opportunities? J. Ind. Ecol. 14, 529-532 (2010).

11. McAloone, T.C., Andreasen, M.M.: Design for utility, sustainability and societal virtues: developing product service systems. In: Proceedings of DESIGN 2004, the 8th International Design Conference, Dubrovnik, Croatia (2004).

12. Ernzer, M., Grüner, C., Birkhofer, H.: Implementation of DFE in the Daily Design Work: An Approach Derived From Surveys. In: Volume 4: 14th International Conference on Design Theory and Methodology, Integrated Systems Design, and Engineering Design and Culture. p. 345. ASME (2002).

13. Le Pochat, S., Bertoluci, G., Froelich, D.: Integrating ecodesign by conducting changes in SMEs. J. Clean. Prod. 15, 671-680 (2007).

14. EMF: Towards the Circular Economy Vol. 1: an economic and business rationale for an accelerated transition. Ellen MacArthur Foundation (2012).

15. Hernandez-Pardo, R.J., Bhamra, T.A., Bhamra, R.S.: Designing sustainable product service systems in SMEs. Int. J. Des. Manag. Prof. Pract. 6, 57-71 (2013).

16. Tukker, A.: Product services for a resource-efficient and circular economy - A review, (2015).

17. Lelah, A., Mathieux, F., Brissaud, D.: Contributions to eco-design of machine-to-machine product service systems: the example of waste glass collection. J. Clean. Prod. 19, 10331044 (2011).

18. Lindahl, M., Sundin, E., Sakao, T.: Environmental and economic benefits of Integrated Product Service Offerings quantified with real business cases. J. Clean. Prod. 64, 288-296 (2014).

19. Sanyé-Mengual, E., Pérez-López, P., González-García, S., Lozano, R.G., Feijoo, G., Moreira, M.T., Gabarrell, X., Rieradevall, J.: Eco-designing the use phase of products in sustainable manufacturing: The importance of maintenance and communication-to-user strategies sanyé-mengual et al. Eco-designing the use phase. J. Ind. Ecol. 18, 545-557 (2014).

20. Aurich, J.C., Fuchs, C., Wagenknecht, C.: Life cycle oriented design of technical ProductService Systems. J. Clean. Prod. 14, 1480-1494 (2006).

21. Sakao, T., Lindahl, M.: A method to improve integrated product service offerings based on life cycle costing. CIRP Ann. - Manuf. Technol. 64, 33-36 (2015).

22. Ramani, K., Ramanujan, D., Bernstein, W.Z., Zhao, F., Sutherland, J., Handwerker, C., Choi, J.-K., Kim, H., Thurston, D.: Integrated Sustainable Life Cycle Design: A Review. J. Mech. Des. 132, 91004-91015 (2010).

23. Siemens Product Lifecycle Management Software Inc.: What is PLM Software?, https://www.plm.automation.siemens.com/en_us/plm/index.shtml.

24. Germani, M.: G.EN.ESI Report Summary, http://cordis.europa.eu/result/rcn/171703_en.html. 
25. G.EN.ESI Consortium: G.EN.ESI Publications, http://genesi-fp7.eu/the-project/publications/.

26. Germani, M., Mandolini, M., Marconi, M., Dufrene, M., Zwolinski, P.: A Methodology and a Software Platform to Implement an Eco-Design Strategy in a Manufacturing Company. In: Volume 4: 18th Design for Manufacturing and the Life Cycle Conference; 2013 ASME/IEEE International Conference on Mechatronic and Embedded Systems and Applications. ASME (2013).

27. Favi, C., Germani, M., Marconi, M., Mengoni, M.: Innovative software platform for ecodesign of efficient electric motors. J. Clean. Prod. 37, 125-134 (2012).

28. Rossi, M., Germani, M., Zamagni, A.: Review of ecodesign methods and tools. Barriers and strategies for an effective implementation in industrial companies. J. Clean. Prod. 129, 361373 (2016). 